\title{
Sleep-disordered breathing and upper airway size in pregnancy and post-partum
}

\author{
B. Izci*, M. Vennelle*, W.A. Liston\#, K.C. Dundas\#, A.A. Calder ${ }^{\#}$ and N.J. Douglas*
}

ABSTRACT: Sleep-disordered breathing and snoring are common in pregnancy. The aim of this study was to determine whether pregnancy was associated with upper airway narrowing.

One-hundred females in the third trimester of pregnancy were recruited and 50 agreed to be restudied 3 months after delivery. One-hundred nonpregnant females were also recruited. Upper airway dimensions were measured using acoustic reflection.

Snoring was less common in nonpregnant $(17 \%)$ than pregnant females $(41 \%$; odds ratio (OR) 3.34; $95 \%$ confidence interval $(\mathrm{Cl})$ 1.65-6.74) and returned to nonpregnant levels after delivery (18\%; OR $0.15 ; 95 \% \mathrm{Cl} 0.06-0.40)$. Pregnant females had significantly smaller upper airways than nonpregnant females at the oropharyngeal junction when seated (mean difference $0.12 ; 95 \% \mathrm{CI}$ $0.008-0.25$ ), and smaller mean pharyngeal areas in the seated (mean difference $0.14 ; 95 \% \mathrm{Cl}$ $0.001-0.28$ ), supine (mean difference $0.11 ; 95 \% \mathrm{Cl} 0.01-0.22$ ) and lateral postures (mean difference $0.13 ; 95 \% \mathrm{Cl} 0.02-0.24$ ) compared with the nonpregnant females. Pregnant females had smaller mean pharyngeal areas compared with post-partum in the seated (mean difference 0.18; 95\% $\mathrm{Cl} 0.02-0.32$ ), supine (mean difference 0.20 ; $95 \% \mathrm{Cl} 0.06-0.35$ ) and lateral postures (mean difference 0.26 ; $95 \% \mathrm{Cl} 0.12-0.39$ ).

In conclusion, this study confirmed increased snoring and showed narrower upper airways during the third trimester of pregnancy.

KEYWORDS: Post-partum, sleep-disordered breathing, snoring, third trimester, upper airway

noring and sleep-disordered breathing (SDB) are 2-3 times more common in pregnant than nonpregnant females. Selfreported snoring occurs in $14-28 \%$ of females in the third trimester of pregnancy and in $\sim 75 \%$ of pre-eclamptic females compared with $4-14 \%$ of nonpregnant females of similar age [1-4]. FRANKLIN et al. [2] reported that pregnant females who snored had increased rates of hypertension, pre-eclampsia and intra-uterine growth restriction of the foetus and babies with lower Apgar scores.

The mechanisms underlying the increase in snoring during pregnancy are unclear. BRADLEY et al. [5] reported that snorers with or without obstructive sleep apnoea have narrower upper airways (UAs) than nonsnorers even when awake. In pregnancy, the physiological changes potentially predisposing to increased resistance [2] and reduced cross-sectional area of the UAs [4] include the following: weight gain [2, 6-9]; a decreased functional residual capacity (FRC) due to mass displacement of the diaphragm [9-11]; pharyngeal oedema of pregnancy [2-4, 12]; and, possibly, the effect of sleep deprivation or fragmentation on pharyngeal dilator muscle activity [13] and UA collapsibility [14].
Snoring may subside within a few months of delivery [15]. Lung function studies have shown that both closing capacity and FRC are lower in pregnancy compared with the post-partum period $[10,11]$. However, there have been no studies measuring the effect of pregnancy or the post-partum period on UA dimension. In a previous study with a three-way comparison [4], it was shown that pre-eclamptic females had UA narrowing compared with nonpregnant or normal pregnant females, and there was a nonsignificant trend for pregnant females to have narrower airways than nonpregnant females when in the supine position. The current authors have now, therefore, performed a larger more powerful study to compare UA size in pregnant and nonpregnant females, and also a prospective study to clarify possible changes in UA calibre after pregnancy.

\section{MATERIAL AND METHODS \\ Subjects}

A total of 138 females aged 18-41 yrs in the third trimester of their pregnancies attending the Maternity Dept (Royal Infirmary of Edinburgh, Edinburgh, UK) were consecutively considered for participation in this study. One-hundred of
AFFILIATIONS

Depts of *Sleep Medicine, and

\#Reproductive and Developmental Sciences, University of Edinburgh, Scotland, UK.

\section{CORRESPONDENCE}

N.J. Douglas

Respiratory Medicine Royal Infirmary

51 Little France Crescent

Edinburgh EH16 4SA UK

Fax: 441312421776

E-mail: n.j.douglas@ed.ac.uk

Received

December 262004

Accepted after revision:

September 282005

\section{SUPPORT STATEMENT}

This study received financial support from the Cunningham Trust (St Andrews, UK) and International Sleep Research Foundation Inc. (Houston, TX, USA). 
these took part in the study, whereas 38 were excluded because they had twins, essential or gestational hypertension, or preeclampsia. One-hundred nonpregnant females aged 18-43 yrs were randomly selected from advertisement respondents, mainly hospital staff. Those with severe asthma or other respiratory illness, i.e. two pregnant females (one with cystic fibrosis and one with severe asthma) and one nonpregnant female with a respiratory infection, were excluded. None of the pregnant or the nonpregnant females had participated in the current authors' previous study [4].

All of the pregnant females studied were informed about the possibility of the follow-up study when initially studied. At least 3 months after their delivery, the subjects were sent a letter (including questionnaires) and contacted by telephone to invite them to take part in the follow-up study. Fifty agreed to be restudied. The rest were not able to attend the follow-up study due to the demands on new mothers, travel problems, moving house, taking care of other children or recommencing work.

All gave written, informed consent to the studies which were approved by the Ethical Advisory Committee (Lothian Health Board).

\section{Study design}

This is a cross-sectional and prospective study, which was designed to examine the effect of pregnancy on UA dimension. In this study, all subjects were asked to answer questions about snoring and breathing pauses, and sleepiness. They also had their UA measured. Fifty pregnant females' UA dimensions were measured again at least 3 months after their delivery.

\section{Protocol}

\section{Questionnaires}

All subjects and their partners completed a standard sleep questionnaire, including Epworth Sleepiness Scale (ESS) and a five-point Likert scale for refreshment.

The ESS provides a subjective estimate of patients' daytime sleepiness in eight everyday situations (each question scores 0 (never) to 3 (high chance); total ranging 0-24). It has been shown to have good test-retest reliability $(\mathrm{r}=0.82)$ and internal consistency (Cronbach alpha $=0.74-0.88)$ [16, 17].

The question "How refreshed do you feel on wakening in the morning regardless of sleep duration?" was rated on a fivepoint Likert scale from 1 (very unrefreshed) to 5 (fully refreshed). This question is widely used in sleep units to evaluate individuals for possible SDB. A similar form (or the visual analogue scale) for refreshment, snoring and daytime sleepiness has been used by other researchers successfully $[15,18,19]$. It has been shown that this question has significant correlations with excessive daytime sleepiness [18] and snoring [19].

The subjects and their partners also answered questions on snoring and breathing pauses of females, and weight prepregnancy. Pregnant females were asked to rate some responses for the time before and after pregnancy to allow comparisons. Snoring frequency and breathing pauses were rated prepregnancy and during the last month on a five-point scale comprising "never", "rare" (1-2 nights per month), "occasional" (1-2 nights per week), "often" (3 nights per week), "frequent or always" ( $>3$ nights per week) and "do not know".
Criteria for snoring and breathing pauses

For snoring and breathing pauses, the higher of the frequencies reported by the subject and partner was used. Snoring and breathing pauses were considered to exist in subjects if rated often or always. Those who snored often or always ( $\geqslant 3$ days per week) were defined as habitual snorers.

To assess possible bias, since 45 out of 100 nonpregnant females were without a current partner, a second questionnaire was sent to an occasional room-sharer of these subjects, asking for information on snoring and breathing pauses. The 20 returned questionnaires showed no difference between the partners' and these subjects' reports of snoring (odds ratio (OR) 0.3 ; 95\% confidence interval (CI) $0.1-2.2 ; \mathrm{p}=0.25$ ) and breathing pauses (OR 0.9; 95\% CI 0.7-1.1; $\mathrm{p}=0.059$ ).

\section{Measurements}

All subjects had their height, weight, waist/hip ratio, neck circumferences, blood pressure (BP) and UA calibre measured. These measurements and questionnaires were repeated in the post-partum period.

Blood pressure was recorded using a mercury sphygmomanometer (Korotkoff Phase IV) seated with the right arm at the level of the patient's heart before the upper airway measurement. All measurements were taken in the afternoon.

\section{Upper airway measurement}

Each subject had UA calibre measured using the current authors' previously described acoustic reflection technique [20-22]. Five measurements were recorded in each position (i.e. seated, supine and left lateral), and all were stored. The traces were anonymised, and randomised and scored by a single observer blinded to case status. This observer decided which traces were technically satisfactory, and averaged the results, deriving measurements of oropharyngeal junction (OPJ) area, mean pharyngeal area from the OPJ to the glottis (Ap,mean; $\left.\mathrm{cm}^{2}\right)$, and mean pharyngeal volume $\left(\mathrm{cm}^{3}\right)$ as the integrated area under the curve between the OPJ and glottis (fig. 1) [20-22].

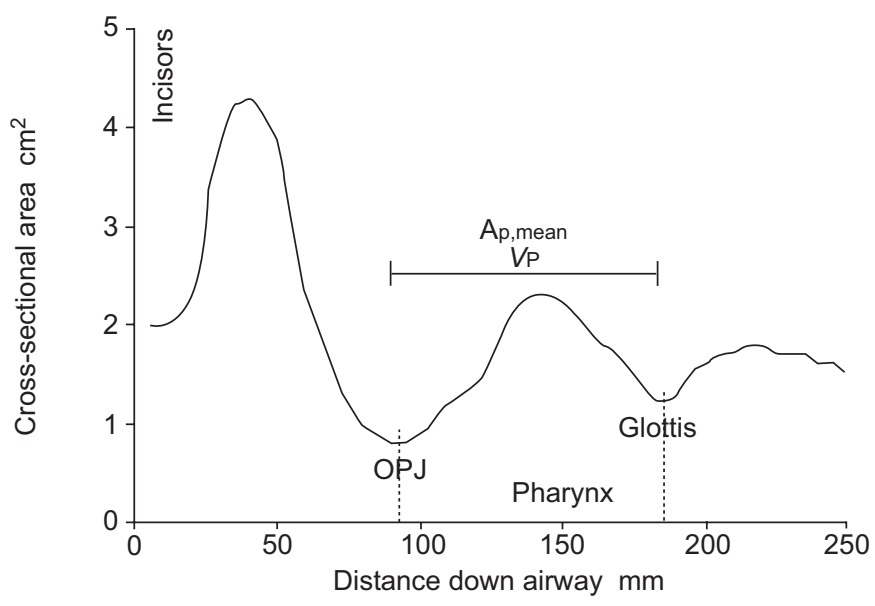

FIGURE 1. Example trace of upper airway produced by acoustic reflectance OPJ: oropharyngeal junction; Ap,mean: mean pharyngeal cross-sectional area; $V_{p}$ pharyngeal volume. 


\section{Statistical analysis}

The statistical significance between the groups was assessed using unpaired t-test and Chi-squared tests for independent variables, and paired t-test and McNemar test for dependent samples. Correlations were performed using the Pearson's coefficient of correlation. With sample sizes of $n=200$, power of $88 \%$ was provided to detect a $13 \%$ difference in UA crosssectional area at the OPJ level [21]. Results are presented as mean \pm SD or mean \pm SEM and mean differences with $95 \%$ CI, or as percentages with OR and 95\% CI. A p-value $<0.05$ was used to indicate statistical significance.

\section{RESULTS}

\section{Subject characteristics}

The pregnant and nonpregnant subjects did not differ in terms of age or height, or pre-pregnancy weight (table 1). There was also no difference between the pregnant and the nonpregnant subjects in measured neck circumference on the day UA dimensions were measured. However, nonpregnant females tended to have a higher body mass index (BMI) than that reported by pregnant females prior to their pregnancy $(p=0.059$; table 1$)$. The mean $\pm S D$ duration of gestation of all the pregnant females who were recruited was $36 \pm 3$ weeks.

\section{TABLE 1 Characteristics of subjects studied}

\begin{tabular}{|c|c|c|c|}
\hline & Nonpregnant & Pregnant & p-value \\
\hline Subjects n & 100 & 100 & \\
\hline Age yrs & $31.5 \pm 6.5$ & $30 \pm 6$ & $>0.1$ \\
\hline Height $\mathrm{m}$ & $1.64 \pm 0.1$ & $1.65 \pm 0.1$ & $>0.4$ \\
\hline Pre-pregnancy weight kg & $66.6 \pm 12$ & $64 \pm 11.5$ & $>0.1$ \\
\hline Pre-pregnancy BMI $\mathbf{k g} \cdot \mathrm{m}^{-2}$ & $24.8 \pm 4.7$ & $23.6 \pm 4$ & 0.059 \\
\hline Pregnancy weight kg & & $76 \pm 13$ & \\
\hline Pregnancy BMI $\mathbf{k g} \cdot \mathrm{m}^{-2}$ & & $28 \pm 4$ & \\
\hline Neck circumference cm & $33 \pm 2$ & $33.4 \pm 2$ & $>0.1$ \\
\hline Waist/hip ratio & $0.8 \pm 0.07$ & $1 \pm 0.06$ & $<0.001$ \\
\hline Systolic BP ${ }^{\#}$ mmHg & $108 \pm 2$ & $115 \pm 1$ & 0.001 \\
\hline Diastolic BP\# mmHg & $72 \pm 1$ & $74 \pm 1$ & $>0.1$ \\
\hline
\end{tabular}

Data are presented as mean $\pm \mathrm{SD}$, unless otherwise stated. BMI: body mass index; BP: blood pressure. ${ }^{\#}$ : mean \pm SEM.
The pregnant subjects, who were restudied post-partum, were compared with those who were not restudied. The groups did not differ in terms of the main demographic characteristics, which included the mean duration of gestation (those restudied $36 \pm 4$ versus $36 \pm 4$ weeks; $p=0.25$ ), neck circumference $(33.6 \pm 2$ versus $33.4 \pm 2 \mathrm{~cm} ; \mathrm{p}=0.58)$, height $(1.66 \pm 0.1$ versus $1.65 \pm 0.1 \mathrm{~m} ; \mathrm{p}=0.38)$, pregnancy BMI $(28 \pm 4$ versus $27 \pm 5$ $\left.\mathrm{kg} \cdot \mathrm{m}^{-2} ; \mathrm{p}=0.21\right)$, pre-pregnancy BMI $(24 \pm 4$ versus $23 \pm 4$ $\left.\mathrm{kg} \cdot \mathrm{m}^{-2} ; \mathrm{p}=0.13\right)$ and pre-pregnancy weight $(66 \pm 11$ versus $63 \pm 11 \mathrm{~kg} ; \mathrm{p}=0.11$ ), but were older (those restudied $33 \pm 4$ versus $28 \pm 6$ yrs; $\mathrm{p}<0.001)$. They did not differ in the following clinical features: snoring (OR 2.1; 95\% CI 0.9-4.7; $\mathrm{p}=0.09$ ), breathing pauses (OR $0.5 ; 95 \%$ CI $0.1-1.7 ; \mathrm{p}=0.25$ ) or UA crosssectional areas (all $\mathrm{p}>0.07$ ).

\section{The prevalence of snoring and breathing pauses}

The prevalence of snoring frequency is presented in table 2 . "Never" and "occasional snoring" answers were considered as nonsnoring in order to compare snoring status between habitual snorers and nonsnorers. A total of $17 \%$ of the nonpregnant females were reported to snore compared with $41 \%$ of the pregnant subjects (OR 3.34; 95\% CI 1.65-6.74; $\mathrm{p}<0.001)$. Twelve per cent of the pregnant females suffered from habitual snoring prior to becoming pregnant (OR 0.67; 95\% CI $0.28-1.58 ; \mathrm{p}=0.35$ compared with nonpregnant females).

A total of $31 \%$ of pregnant and $22 \%$ of nonpregnant subjects, and their partners, did not know if the subjects had breathing pauses. Sixty-four (74\%) of the nonpregnant and $44(54 \%)$ of the pregnant subjects never had breathing pauses, two $(2 \%)$ nonpregnant and four (5\%) pregnant subjects occasionally had breathing pauses, whereas two (2\%) nonpregnant and eight $(10 \%)$ pregnant subjects reported that they had breathing pauses frequently or always. Again, "never" and "occasional" answers were taken to mean no breathing pauses. Three per cent of nonpregnant subjects had been reported to have breathing pauses in comparison with $14 \%$ of pregnant subjects (OR 5.5; 95\% CI 1.12-27.1; $\mathrm{p}=0.02$ ). Breathing pauses were reported in $19 \%$ of snoring pregnant subjects, as compared with $12 \%$ of the nonsnoring pregnant subjects (OR $1.77 ; 95 \% \mathrm{CI}$ 0.39-7.97; $\mathrm{p}=0.46)$.

In the post-partum group, habitual snoring occurred in $11 \%$ before pregnancy and $59 \%$ in the third trimester (OR 0.08;

\section{TABLE 2 Snoring frequency by pregnancy status}

Snoring frequency

\begin{tabular}{|c|c|c|c|c|}
\hline & \\
\hline & Never & Occasionally & Frequently/always & Don't know \\
\hline Nonpregnant females & $58(62)$ & $15(16)$ & $15(16)$ & $5(5)$ \\
\hline Pregnant females before pregnancy & $57(64)$ & $16(18)$ & $10(11)$ & $6(7)$ \\
\hline Post-partum females & $31(69)$ & $5(11)$ & $8(18)$ & $1(2)$ \\
\hline Post-partum females in pregnancy & $11(22)$ & $9(18)$ & $29(59)$ & \\
\hline
\end{tabular}

Data are presented as $\mathrm{n}(\%)$ 
95\% CI 0.03-0.24; $\mathrm{p}<0.001)$. After delivery, the percentage decreased to $18 \%$ (OR $0.15 ; 95 \%$ CI $0.06-0.40 ; \mathrm{p}<0.001$ compared with pregnancy level). Fifteen per cent of pregnant subjects reported breathing pauses in the third trimester of pregnancy, whereas only $5 \%$ of them had reported breathing pauses in post-partum (OR 0.31; 95\% CI 0.06-1.62; $\mathrm{p}<0.001$ ). None of them reported breathing pauses before pregnancy (OR $0.85 ; 95 \%$ CI $0.75-0.97 ; \mathrm{p}<0.001$ compared with pregnancy period). Twenty-five per cent of snoring females reported that they had breathing pauses compared with $0 \%$ of nonsnoring females in the pregnancy period (OR 1.33; 95\% CI 1.06-1.68; $\mathrm{p}<0.001)$.

\section{Snoring in pregnant and nonpregnant females and females in post-partum period}

Pregnant subjects who snored were heavier (snorers: $68 \pm 11$ $\mathrm{kg}$; nonsnorers: $62 \pm 10 \mathrm{~kg}$; $\mathrm{p}=0.01$ ), had higher BMIs before pregnancy (snorers: $25 \pm 5$; nonsnorers: $23 \pm 4 ; p=0.008$ ) and during pregnancy (weight snorers: $79 \pm 11 \mathrm{~kg}$; nonsnorers: $73 \pm 13 \mathrm{~kg} ; \mathrm{p}=0.04$; BMI snorers: $29 \pm 4$; nonsnorers: $27 \pm 4$; $\mathrm{p}=0.03)$. Snoring pregnant subjects had a tendency to have a larger neck circumference than nonsnorers (snorers: $34 \pm 2 \mathrm{~cm}$; nonsnorers: $33 \pm 2 \mathrm{~cm} ; \mathrm{p}=0.052$ ). Also, snoring females in postpartum had larger neck circumferences (snorers: $34 \pm 2 \mathrm{~cm}$; nonsnorers: $32 \pm 2 \mathrm{~cm}$; $\mathrm{p}=0.008$ ), but $\mathrm{BMI}$ and weight did not change between snorers and nonsnorers in post-partum (both $\mathrm{p}>0.07)$. With regard to BMI, weight and neck circumferences in nonpregnant females, there were no significant differences between snorers and nonsnorers (all $\mathrm{p} \geqslant 0.42$ ).

Habitual snoring was not associated with any UA size differences in either pregnancy, post-partum or nonpregnant females (all $\mathrm{p} \geqslant 0.12$ ).

\section{Comparative study}

Differences in UA dimensions between nonpregnant and pregnant subjects

Pregnant females had significantly smaller UAs at the OPJ when seated and smaller mean pharyngeal areas in the seated, supine and lateral postures compared with the nonpregnant females (table 3). All other UA dimensions in all postures were numerically narrower in pregnancy, but these differences were not statistically significant.

\section{Follow-up study}

When 50 pregnant females were restudied in post-partum, they had lower BMI $\left(28 \pm 4\right.$ versus $\left.25 \pm 4 \mathrm{~kg} \cdot \mathrm{m}^{-2} ; \mathrm{p}<0.001\right)$ and neck circumference $(34 \pm 2$ versus $33 \pm 2 \mathrm{~cm} ; \mathrm{p}<0.001)$.

Comparison of UA dimensions in post-partum period and third trimester of pregnancy

Subjects in the third trimester of pregnancy had smaller Ap,mean compared with post-partum period in all three postures: seated, supine and lateral (table 4). On lying down, the UAs at OPJ narrowed more markedly during pregnancy than in the post-partum period (table 4).

\section{$B P$ in third trimester of pregnancy}

Pregnant females had higher systolic BP than nonpregnant females (table 1). Pregnant females who participated in the follow-up study had higher systolic BP in pregnancy than post-partum (mean \pm SEM $116 \pm 2$ versus $104 \pm 2 \mathrm{mmHg}$; $\mathrm{p}<0.001)$.

Relationship between BP and airway size

In the nonpregnant females, there were negative correlations between Ap,mean in the seated $(\mathrm{r}=-0.23 ; \mathrm{p}=0.05)$ and supine

\section{TABLE 3 Airway calibre measures for pregnant and nonpregnant females}

\begin{tabular}{|c|c|c|c|c|c|}
\hline & \multirow[t]{2}{*}{ Nonpregnant ${ }^{\#}$} & \multirow[t]{2}{*}{ Pregnant $^{\#}$} & \multicolumn{2}{|c|}{ Differences } & \multirow[t]{2}{*}{ p-value } \\
\hline & & & Mean & $95 \% \mathrm{Cl}$ & \\
\hline \multicolumn{6}{|c|}{ Upper airway seated } \\
\hline OPJ $\mathrm{cm}^{2}$ & $1.39 \pm 0.05$ & $1.27 \pm 0.04$ & 0.12 & $0.008-0.25$ & $<0.04$ \\
\hline Ap, mean $\mathrm{cm}^{2}$ & $1.84 \pm 0.05$ & $1.70 \pm 0.05$ & 0.14 & $0.001-0.28$ & $<0.05$ \\
\hline OPJ $\mathrm{cm}^{2}$ & $1.15 \pm 0.04$ & $1.07 \pm 0.03$ & 0.08 & $-0.01-0.17$ & 0.09 \\
\hline Ap, mean $\mathrm{cm}^{2}$ & $1.62 \pm 0.04$ & $1.51 \pm 0.03$ & 0.11 & $0.01-0.22$ & $<0.03$ \\
\hline$V_{p} \mathrm{~cm}^{3}$ & $17.54 \pm 0.54$ & $16.35 \pm 0.49$ & 1.19 & $-0.26-2.63$ & 0.10 \\
\hline \multicolumn{6}{|c|}{ Upper airway lateral } \\
\hline OPJ $\mathrm{cm}^{2}$ & $1.23 \pm 0.03$ & $1.17 \pm 0.03$ & 0.06 & $-0.03-0.15$ & 0.18 \\
\hline Ap, mean $\mathrm{cm}^{2}$ & $1.71 \pm 0.04$ & $1.58 \pm 0.04$ & 0.13 & $0.02-0.24$ & 0.02 \\
\hline OPJ \% & $12 \pm 4$ & $9 \pm 3$ & 2 & $-8-12$ & 0.63 \\
\hline Ap,mean \% & $9 \pm 3$ & $6 \pm 3$ & 3 & $-5-11$ & 0.46 \\
\hline$V_{p} \%$ & $7 \pm 3$ & $6 \pm 4$ & 2 & $-9-12$ & 0.78 \\
\hline
\end{tabular}

Data are presented as mean \pm SEM, unless otherwise stated. Cl: confidence interval; OPJ: oropharyngeal junction; Ap,mean: mean pharyngeal cross-sectional area; $V_{p}$ : pharyngeal volume. ${ }^{*}: n=100$. 
TABLE 4 Airway calibre measures for pregnant and post-partum females

\begin{tabular}{|c|c|c|c|c|c|}
\hline & \multirow[t]{2}{*}{ Post-partum ${ }^{\#}$} & \multirow[t]{2}{*}{ Pregnant $^{\#}$} & \multicolumn{2}{|c|}{ Differences } & \multirow[t]{2}{*}{ p-value } \\
\hline & & & Mean & $95 \% \mathrm{Cl}$ & \\
\hline \multicolumn{6}{|c|}{ Upper airway seated } \\
\hline OPJ $\mathrm{cm}^{2}$ & $1.32 \pm 0.07$ & $1.30 \pm 0.05$ & 0.02 & $-0.14-0.17$ & 0.85 \\
\hline Ap, mean $\mathrm{cm}^{2}$ & $1.80 \pm 0.06$ & $1.62 \pm 0.05$ & 0.18 & $0.02-0.32$ & $<0.03$ \\
\hline OPJ $\mathrm{cm}^{2}$ & $1.12 \pm 0.04$ & $1.06 \pm 0.04$ & 0.06 & $-0.07-0.19$ & 0.36 \\
\hline Ap, mean $\mathrm{cm}^{2}$ & $1.67 \pm 0.05$ & $1.47 \pm 0.05$ & 0.20 & $0.06-0.35$ & 0.007 \\
\hline$V_{p} \mathrm{~cm}^{3}$ & $17.09 \pm 0.79$ & $16.84 \pm 0.71$ & 0.25 & $-1.97-2.48$ & 0.82 \\
\hline \multicolumn{6}{|c|}{ Upper airway lateral } \\
\hline OPJ $\mathrm{cm}^{2}$ & $1.22 \pm 0.05$ & $1.18 \pm 0.04$ & 0.057 & $-0.47-0.16$ & 0.28 \\
\hline Ap, mean $\mathrm{cm}^{2}$ & $1.75 \pm 0.05$ & $1.49 \pm 0.04$ & 0.26 & $0.12-0.39$ & 0.001 \\
\hline Ap,mean \% & $9 \pm 3$ & $5 \pm 6$ & 4 & $-11-19$ & 0.61 \\
\hline$V_{p} \%$ & $9 \pm 5$ & $2 \pm 8$ & 6 & $-15-27$ & 0.55 \\
\hline
\end{tabular}

$(\mathrm{r}=-0.23 ; \mathrm{p}=0.05)$ postures with diastolic BP, but no correlations between systolic BP and UA sizes. In the pregnant females, there were negative correlations between systolic BP with seated $(r=-0.2 ; p=0.05)$, supine $(r=-0.3 ; p=0.01)$ and lateral $(\mathrm{r}=-0.3 ; \mathrm{p}=0.05) \mathrm{Ap}$,mean and lateral OPJ $(\mathrm{r}=-0.23$; $\mathrm{p}=0.05$ ). Diastolic BP did not correlate with any UA sizes. In the post-partum females, there were no significant correlations.

\section{Sleepiness and refreshment}

Mean ESS scores were higher during pregnancy than reported pre-pregnancy scores (mean \pm SEM pregnancy: $7 \pm 1$; prepregnancy: $4 \pm 1 ; \mathrm{p}<0.001)$. Pregnant females also had higher ESS scores than nonpregnant females $(5 \pm 1 ; p=0.001)$. In the follow-up study, females had higher ESS scores in pregnancy than in post-partum (pregnancy: $8 \pm 1$; post-partum: $6 \pm 1$; $\mathrm{p}=0.008)$.

Pregnant females felt more refreshed on waking in the morning before pregnancy than during the third trimester of pregnancy (pre-pregnancy: $3.6 \pm 0.1$; pregnancy: $2.8 \pm 0.1$; $\mathrm{p}<0.001)$. However, there were no significant differences in refreshment between nonpregnant and pregnant females or between the pregnancy and post-partum period $(p \geqslant 0.14)$.

In the pregnancy and post-partum period, snoring was not associated with either ESS or refreshment score (both $p>0.3$ ). In nonpregnant females, snorers were not sleepier than nonsnorers, but they felt less refreshed than nonsnorers on waking in the morning (snorers: $2.3 \pm 0.2$; non-snorers: $3.1 \pm 0.1 ; \mathrm{p}<0.001$ ).

\section{DISCUSSION}

This study shows that UAs are significantly narrower in females in the third trimester of pregnancy. This was found both by comparison with nonpregnant females and by repeated measurements post-partum, when the UA widens again. All nine measures of UA calibre were numerically smaller in the third trimester of pregnancy, and four of these differences were significant, including at least one of the measurements in each posture. In the follow-up study, three of the UA dimensions were significantly narrower in the third trimester of pregnancy than post-partum. On lying down, the OPJ narrowed more markedly during pregnancy. Although the changes were consistent, they were small, with no greater than $15 \%$ narrowing between pregnant and nonpregnant females, and between the pregnancy and post-partum period. However, the prevalence of habitual snoring, which often accompanied clinically important SDB, was considerably higher in pregnant females, strongly supporting the current authors' observation of UA narrowing in pregnancy.

There are several studies on SDB in pregnancy, but most are based on questionnaires [1,2] or clinical examinations [12] or focused on pre-eclampsia [3, 4, 23]. Therefore, this study would seem to be one of the first that presents both objective and subjective measurements regarding SDB in healthy pregnant females.

In the current study, findings regarding frequent snoring increased up to $59 \%$ in the third trimester compared with the pre-pregnancy $(12 \%)$ and the post-partum period $(18 \%)$, and breathing pauses were reported in $14-15 \%$ in the third trimester of pregnancy. Although the current study confirms the results from previous studies and case reports $[1-4,15,24$, 25], the percentage of snoring is higher in this study than in others because previous studies focus on the results from only the females [1] or only the partner [15], whereas the current study combined both reports.

The objectively narrower UA in pregnancy is compatible with the suggestion of reduced pharyngeal dimensions during 
pregnancy demonstrated using visual inspection, classified according to the Mallampati score [12]. The finding that the UA is narrowed in the third trimester of pregnancy is also consistent with weight gain [2, 6-8] and abdominal mass loading, resulting in decreased lung volume and trachea shortening [7, 9, 26]. FRANKLIN et al. [2] and MAASILTA et al. [6], as well as the present study, found that habitual snorers were significantly heavier than nonsnorers before and during pregnancy. This outcome suggests that both pre-pregnancy BMI and gestational weight gain have an important role in the development of SDB in pregnancy. This finding was supported by WELCH et al. [8], who demonstrated that cross-sectional area increased with weight loss in normal females, and observed, as did HOFFSTEIN et al. [7], that weight loss lowered the diaphragm and increased FRC.

In addition to pre-pregnancy BMI and gestational weight gain, fat deposition that infiltrates pharyngeal muscle tissue or soft tissue deposition in the neck and around UA may cause UA narrowing in pregnancy $[4,27]$. In a pregnancy study, ear, nose and throat examination revealed nasal mucosal engorgement at 6 months of pregnancy [28]. PIEN et al. [29] showed that neck circumferences increased during pregnancy, a finding which the current authors confirmed and strengthened by showing a decrease in neck size post-partum. SCHWAB et al. [26] have highlighted the importance of the lateral pharyngeal walls in mediating UA calibre together with the tongue and soft palate in snorers. The predominant anatomical abnormality can also be an important factor underlying UA narrowing in pregnant females. In a recent study, physical examination showed that snoring pregnant females had abnormal oropharyngeal anatomy with a small oropharynx in the first trimester of pregnancy [28].

In this study, systolic BP was higher in pregnant females than nonpregnant females. Pregnant females who took part in the follow-up study also had higher systolic BP in pregnancy than post-partum. EDWARDS et al. [3] found an association between UA narrowing during sleep and BP surges in females with preeclampsia. The present study extends these observations by indicating weak correlations between UA size during wakefulness and BP in these groups, but none explained $>9 \%$ of the variance in $\mathrm{BP}$.

Females in the third trimester of pregnancy had higher ESS scores than in their pre-pregnancy and post-partum periods and felt less refreshed on awakening in the morning in the third trimester of pregnancy than in the pre-pregnancy period. Pregnant females also had higher ESS scores than nonpregnant females. Having stated this, the mean ESS score of pregnant females did not reach the usual level for excessive daytime sleepiness derived from adult studies (ESS >10) [16, 17]. However, BALDWIN et al. [18] reported that females were less likely to have an ESS score $>10$ and were more likely to report feeling unrested. Therefore, it can be suggested that pregnant females are relatively sleepy, and this is not surprising as difficulty in sleeping during pregnancy is well documented [16, 15, 23-25, 28].

The current study has several limitations. First, the results reported in this study were obtained during wakefulness. Measurements using this technique, however, correlate well with snoring and disturbed breathing during sleep [5, 21, 27].
Differences measured during wakefulness do not necessarily predict differences during sleep, but this technique has shown narrower airways in awake patients with obstructive sleep apnoea-hypopnoea syndrome than in snorers [5, 7, 21], and also shows that awake snorers have narrower UAs than nonsnorers [5]. Thus, the results of acoustic reflection during wakefulness have been shown to predict differences in airway calibre and function during sleep [5, 7, 21, 27].

Secondly, the comparative study with healthy nonpregnant females had a cross-sectional design and there are always potential selection biases between the groups of subjects. A cross-sectional study cannot prove potential reasons and consequences, but only proposes reasons when other confounding factors are controlled. In the current study, the factors that may alter UA dimension were controlled, including sex [22, 27, 30], age [22], obesity [6-8, 22], familial factors [31] and sleep state [32]. However, the nonpregnant group tended to have a higher BMI $(p<0.059)$ than the pregnant group reported prior to pregnancy. An increased BMI in the nonpregnant group would bias against the findings of the current study by predisposing to UA narrowing, snoring and apnoeas $[6,7,22,27]$ in the nonpregnant group, so this cannot be a factor in the current findings of the reverse. Indeed, the trend to a difference in BMI could well result from an overoptimistic estimation of pre-pregnancy BMI by the pregnant females. The longitudinal aspect of the study with repeated measurement post-partum adds credence to the current findings in the cross-sectional component. However, the potential recall bias may occur when pregnant females are asked $\geqslant 3$ months later about their pre-pregnancy snoring, breathing pauses, refreshment and ESS scores, although the main outcomes of the study were objective. Another limitation of the current study is the failure to recruit 50 of the 100 females in the second part of the study after delivery. The subjects recruited did not differ from the decliners in terms of snoring or UA characteristics, and it is believed that the observations of widening of UA calibre post-partum are likely to be robust. Another limitation is the number of statistical comparisons performed. There were 24 comparisons in airway size and, thus, by chance alone, $1.2(24 / 20)$ significant differences would have been found at the $p=0.05$ level. In fact, seven differences were found and all in the hypothesised direction. Thus, the large number of comparisons cannot account for the changes found. It must be noted that the BP measurements were limited to single measurements in each subject and, thus, need to be interpreted with care.

The current study shows that pregnant females have statistically significant upper airway narrowing during the third trimester of pregnancy. It is likely that reduced upper airway calibre may contribute to the increased rate of snoring and sleepdisordered breathing in pregnancy. The further clinical significance of these airway calibre changes requires further study.

\section{ACKNOWLEDGEMENTS}

The authors would like to thank the staff of the Dept of Sleep Medicine (University of Edinburgh) for their assistance, the staff and the patients of the Maternity Dept (Simpson Centre for Reproductive Health, Edinburgh) for their help and cooperation, and E. Dolan for secretarial assistance. 


\section{REFERENCES}

1 Loube DI, Poceta JS, Morales MC, Peacock MD, Mitler MM. Self-reported snoring in pregnancy. Association with fetal outcome. Chest 1996; 109: 885-889.

2 Franklin KA, Holmgren PA, Jonsson F, Poromaa N, Stenlund H, Svanborg E. Snoring, pregnancy-induced hypertension, and growth retardation of the fetus. Chest 2000; 117: 137-141.

3 Edwards N, Blyton DM, Kirjavainen T, Kesby GJ, Sullivan CE. Nasal continuous positive airway pressure reduces sleep-induced blood pressure increments in preeclampsia. Am J Respir Crit Care Med 2000; 162: 252-257.

4 Izci B, Riha RL, Martin SE, et al. The upper airway in pregnancy and pre-eclampsia. Am J Respir Crit Care Med 2003; 167: 137-140.

5 Bradley TD, Brown IG, Grossman RF, et al. Pharyngeal size in snorers, nonsnorers, and patients with obstructive sleep apnea. N Engl J Med 1986; 315: 1327-1331.

6 Maasilta P, Bachour A, Teramo K, Polo O, Laitinen LA. Sleep-related disordered breathing during pregnancy in obese women. Chest 2001; 120: 1448-1454.

7 Hoffstein V, Zamel N, Phillipson EA. Lung volume dependence of pharyngeal cross-sectional area in patients with obstructive sleep apnea. Am Rev Respir Dis 1984; 130: 175-178.

8 Welch KC, Foster GD, Ritter CT, et al. A novel volumetric magnetic resonance imaging paradigm to study upper airway anatomy. Sleep 2002; 25: 532-542.

9 Hillman EJ. Otolaryngologic manifestations of pregnancy. Grand Rounds Archive. www.bcm.tmc.edu/oto/grand/ 2295.html. Date last updated: February 2, 1995. Date last accessed: December 25, 2004.

10 Craig DB, Toole MA. Airway closure in pregnancy. Can Anaesth Soc J 1975; 22: 665-672.

11 Holdcroft A, Bevan DR, O'Sullivan JC, Sykes MK. Airway closure and pregnancy. Anaesthesia 1977; 32: 517-523.

12 Pilkington S, Carli F, Dakin MJ, et al. Increase in Mallampati score during pregnancy. Br J Anaesth 1995; 74: 638-642.

13 Leiter JC, Knuth SL, Bartlett D Jr. The effect of sleep deprivation on activity of the genioglossus muscle. Am Rev Respir Dis 1985; 132: 1242-1245.

14 Series F, Roy N, Marc I. Effects of sleep deprivation and sleep fragmentation on upper airway collapsibility in normal subjects. Am J Respir Crit Care Med 1994; 150: 481-485.

15 Guilleminault C, Querra-Salva M, Chowdhuri S, Poyares D. Normal pregnancy, daytime sleeping, snoring and blood pressure. Sleep Med 2000; 1: 289-297.
16 Johns MW. A new method for measuring daytime sleepiness: the Epworth Sleepiness Scale. Sleep 1991; 14: 540-545.

17 Johns MW. Sleepiness in different situations measured by the Epworth Sleepiness Scale. Sleep 1994; 17: 703-710.

18 Baldwin CM, Kapur VK, Holberg CJ, Rosen C, Nieto FJ. Associations between gender and measures of daytime somnolence in the Sleep Heart Health Study. Sleep 2004; 27: 305-311.

19 Zielinski J, Zgierska A, Polakowska M, et al. Snoring and excessive daytime somnolence among Polish middle-aged adults. Eur Respir J 1999; 14: 946-950.

20 Marshall I, Maran NJ, Martin S, et al. Acoustic reflectometry for airway measurements in man: implementation and validation. Physiol Meas 1993; 14: 157-169.

21 Martin SE, Marshall I, Douglas NJ. The effect of posture on airway caliber with the sleep-apnea/hypopnea syndrome. Am J Respir Crit Care Med 1995; 152: 721-724.

22 Martin SE, Mathur R, Marshall I, Douglas NJ. The effect of age, sex, obesity and posture on upper airway size. Eur Respir J 1997; 10: 2087-2090.

23 Connolly G, Razak AR, Hayanga A, Russell A, McKenna P, McNicholas WT. Inspiratory flow limitation during sleep in pre-eclampsia: comparison with normal pregnant and non-pregnant women. Eur Respir J 2001; 18: 672-676.

24 Kowall J, Clark G, Nino-Murcia G, Powell N. Precipitation of obstructive sleep apnea during pregnancy. Obstet Gynecol 1989; 74: 453-455.

25 Lefcourt LA, Rodis JF. Obstructive sleep apnea in pregnancy. Obstet Gynecol Surv 1996; 51: 503-506.

26 Schwab RJ, Gefter WB, Pack AI, Hoffman EA. Dynamic imaging of the upper airway during respiration in normal subjects. J Appl Physiol 1993; 74: 1504-1514.

27 Mohsenin V. Gender differences in the expression of sleepdisordered breathing: role of upper airway dimensions. Chest 2001; 120: 1442-1447.

28 Guilleminault C, Kreutzer M, Chang JL. Pregnancy, sleep disordered breathing and treatment with nasal continuous positive airway pressure. Sleep Med 2004; 5: 43-51.

29 Pien GW, Pack AI, Schwab RJ. Changes in neck size during pregnancy [abstract]. Am J Respir Crit Care Med 2003; 167: $601 \mathrm{~A}$.

30 White DP, Douglas NJ, Pickett CK, Weil JV, Zwillich CW. Sexual influence on the control of breathing. J Appl Physiol 1983; 54: 874-879.

31 Mathur R, Douglas NJ. Family studies in patients with the sleep apnea-hypopnea syndrome. Ann Intern Med 1995; 122: $174-178$.

32 Thurnheer R, Wraith PK, Douglas NJ. Influence of age and gender on upper airway resistance in NREM and REM sleep. J Appl Physiol 2001; 90: 981-988. 